\title{
HOMENAJE A LÉVI-STRAUSS EL HOMBRE SIGNO DE SIGNOS: EL LÉVI-STRAUSS DE OCTAVIO PAZ Julieta Lizaola*
}

RESUMEN: La obra del antropólogo francés tuvo un impacto importante sobre el pensador mexicano quien, en su libro El nuevo festín de Esopo, subraya sus coincidencias y divergencias, en torno al lenguaje, signo de signos; el mito y sus significados; y las metáforas, con sus analogías en música y poesía.

PALABRAS CLAVE: Lévi-Strauss, Octavio Paz, signo, antropología, lenguaje, mito, metáfora
ABSTRACT: This French anthropologist's work had a big impact on the Mexican intellectual. In his book, El nuevo festín de Esopo, he showcases his affinities and disagreements regarding language, sign of signs; myth and meaning, and the metaphors, discussing their analogies in music and poetry.

KEYWORDS: Lévi-Strauss, Octavio Paz, sign, anthropology, language, myth, metaphor.
RECEPCIÓN: 06 de mayo de 2010.

ACEPTACIÓN: 20 de enero de 2011.
* Departamento Académico de Estudios Generales, ITAM. 


\section{HOMENAJE A LÉVI-STRAUSS* EL HOMBRE SIGNO DE SIGNOS: EL LÉVI-STRAUSS DE OCTAVIO PAZ}

Quizá la historia universal es la historia de la diversa entonación de algunas metáforas. Jorge Luis Borges

\section{I}

El impacto, la seducción e inquietud que produjo el pensamiento de LéviStrauss en Octavio Paz quedaron expresadas en su libro Claude LéviStrauss o el nuevo festín de Esopo. En él ofrece su asombro tanto sobre los puntos que le causan el aristotélico placer de encontrarse frente a una razón realizada, como la incertidumbre, e incluso los desacuerdos que le produce el trabajo del antro-

* Claude Lévi Strauss nació el 28 de noviembre del año 1908; su muerte ocurrió el 30 de octubre de 2009. Durante los años 2008 y 2009 se celebraron eventos de reconocimiento a su obra y festejos por su larga vida, en diferentes academias del mundo. El presente texto formó parte del último homenaje realizado en vida del antropólogo, llevado a cabo en la Universidad Autónoma de Zacatecas, realizado en octubre del año pasado y que llevó por título "Lévi-Strauss y las Américas". pólogo francés. Sin duda, estas reflexiones fueron un homenaje del escritor mexicano al pensador que fue Lévi Strauss. Por lo mismo, es pertinente en este año, donde el homenaje por sus 100 años se ha visto vinculado al de su muerte, traer a la memoria los ecos de las cavilaciones de Octavio Paz.

Como es sabido, Paz no era antropólogo, arqueólogo ni etnólogo, pero estas disciplinas formaron, junto con otras, parte de sus intereses centrales: cómo aproximarse a una área del conocimiento casi oceánica que a su vez exige un singular compromiso en cada una de sus sendas. Sin duda la pregunta por el hombre es el lugar privilegiado pero, como ya nos lo mostraría Kant, de enorme envergadura y com- 
plejidad. Preguntarse por el hombre no puede responderse sin preguntarse cómo es que éste conoce, qué es lo que puede hacer, qué es lo le cabe esperar. Desde el giro antropológico del conocimiento no se ha podido sino intentar responder a estas preguntas. El antropólogo es, así, un corredor de caminos sinuosos y laberínticos, aun cuando se declare un determinista, materialista, estructuralista como LéviStrauss. Sin duda cada antropólogo ensaya su propia respuesta y pone su mirada en alguna parte de este conocer, hacer y esperar del hombre.

Lévi-Strauss, en su obra monumental, nos muestra la suya. Nos acerca a lo arduo que resulta elaborar una mínima respuesta y, sin embargo, llega a algunas que detonan que nuestra torre de verdades de mármol científico se tambalee y fracture. Mínimas verdades que aparecen como piedras angulares del conocimiento contemporáneo; estructuras edificadas sobre otras estructuras anteriores; conocimientos construidos en el largo caminar de la vida de miles de generaciones y grupos humanos; esfuerzos sin fin para construir los múltiples mundos cósmicos y terrenales que, como hombres, hemos habitado; objetos sensibles, inteligibles, intercalados con objetos insustanciales, inmateriales, relacionándonos a través de diferentes formas de tiempo; seres superiores, seres protectores o demonios tentado- res o destructores, sentidos y sinsentidos vitales. Gran esfuerzo ha costado identificar el mundo entendido como realidad.

La entreverada red que teje LéviStrauss para atrapar con sus categorías y conceptos parte de la explicación de nuestras formas de vida cultural y civilizatoria deja varios hilos para poder seguirle en su bosque de propuestas y planteamientos que nos conducen a otras verdades. Estos hilos son un respiro para quienes, al no poder seguirle el paso, nos sujetamos a ellos para recuperar el aliento. Sujetados a ellos vamos asumiendo que hay posturas insostenibles. Nos vemos tomados necesariamente por la necesidad de ejercitar la crítica, por el rechazo a la lectura plana de la realidad. Volvemos, entonces, la mirada a la importancia de las narraciones mitopoiéticas, a los mitos cósmicos, y también a los más humildes, a los mitos de la vida cotidiana de una cultura determinada. No todo son grandes metarelatos o esfuerzos por establecer el orden universal, sino también, como en las fábulas de Esopo, verdades claras ocultas tras la rama de un pequeño arbusto. Nosotros los hombre elaboramos mitos de todo tipo y de todos los órdenes, no podemos vivir sino dentro de este tejido de comunicaciones simbólicas. Comunicaciones en gran medida logradas gracias a la presencia del lenguaje. Las sociedades humanas 
son imposibles fuera del mundo simbólico, del mundo de los signos, y con auxilio del lenguaje vamos haciendo que aparezcan, que tomen cuerpo las estructuras objetivadas en que vivimos.

En suma, seguir a Lévi-Strauss es inquietante, tanto por su dificultad, como por sus postulados. Cómo encajar en el cuerpo que las sociedades salvajes, o silvestres, han tenido un pensamiento que en su organización lógica es similar a la nuestra. Cómo aceptar que seguimos edificando tótems, que nuestras verdades están tejidas con pasajes míticos, porque como Platón, aunque seamos racionalistas, positivitas o ilustrados, no podemos prescindir de ellos para narrarnos y estructurarnos la vida social, ni para establecer acciones y conductas determinadas; tampoco hemos dejado de imaginar paraísos ad hoc a nuestras diversas ideologías, ni hemos parado de construir territorios del mal.

El hombre elabora signos, significados y entre ellos el mundo logra sostenerse. El hombre es hombre porque significa y simboliza. Logra que su grupo social sostenga el universo y moverse dentro de él por los senderos que la simbolización le ofrece y le permite. Comparte con el grupo este construir y sostener la realidad. Cada hombre es un signo para otro hombre. Es el signo de la vida. Es el signo de signos.

El Lévi-Strauss de Octavio Paz es el etnólogo, el sujeto que recorre los ríos subterráneos de la cultura, de la civilización. Paz se deja tocar, se deja seducir, y el resultado es la emoción de estar frente a un esfuerzo de enorme envergadura, de una inteligencia desmedida. Cómo puede ser que esto haya ocurrido, parece preguntarse, cómo pudo surgir un pensamiento que haya sacado a la luz los cimientos y mostrarnos que no sabemos edificar clanes, pueblos, ciudades, estados, sino desde ahí, desde las formas más elementales de vincularnos con lo que nos rodea, aunque ahora lo hagamos vestidos de sofisticación. Además, Lévi-Strauss elabora una suerte de síntesis teórica entre el quehacer del antropólogo, el pensar marxista y la tradición budista. Cuestiones que no son fáciles de articular, y por ello mismo, la fascinación en la que sucumbe Paz mientras escribe El nuevo festín de Esopo.

\section{II}

El tema general que conmueve a Paz y le lleva a escribir sus notas reflexivas sobre la Obra de Lévi-Strauss es el siguiente:

I. La intención de elaborar una Teoría general de los signos; es decir, 
una teoría del lugar del hombre en el sistema de la naturaleza y en la inmensidad de vasos comunicantes que conforman una vida social, donde la interrogación por el hombre, su conocer y su hacer, es, a la vez, una interrogación sobre el lenguaje y los significados. En este sentido, debe hacerse un homenaje a Esopo.

Todo lo que nombramos -señala Paz- ingresa al círculo del lenguaje $y$, en consecuencia, a la significación. El mundo es un orbe de significados, un lenguaje. Pero cada palabra posee un significado propio, distinto y contrario a los de las otras palabras. En el interior del lenguaje los significados combaten entre sí, se neutralizan y se aniquilan. La proposición: todo es significativo porque todo lenguaje puede invertirse: todo carece de significación porque todo es lenguaje. ${ }^{1}$

A Paz le maravilla, en el año 1967, la pretensión de Lévi-Strauss de aplicar el método estructural de la lingüística a la antropología. "Ya que el lenguaje no sólo es un fenómeno social, sino que constituye el fundamento de toda sociedad y la expresión social más perfecta del hombre. La posición privilegiada del lenguaje lo convierte en un modelo de la investigación antropológica". ${ }^{2}$ Encuentra, de

${ }^{1}$ Octavio Paz, Corriente alterna, 1968, México, Siglo XXI, p. 8.

${ }^{2}$ Octavio Paz, Lévi-Strauss o el nuevo festín de Esopo, 2008, Barcelona, Seix Barral, p. 16. este modo, una coincidencia cómplice en el antropólogo estructuralista y festina el papel central, arquitectónico, del lenguaje. Y lo sigue por medio de las fuentes que el mismo Lévi-Strauss confiesa y muestra como sus maestros: la geología, el psicoanálisis y el marxismo, no por sus determinismos teóricos, sino por cuanto "los tres demuestran que comprender consiste en reducir un tipo de realidad a otro; que la realidad verdadera no es nunca la más manifiesta", sino que estriba en la estructura subyacente.

Paz toma, entonces, varios temas de la obra de Lévi-Strauss y con ellos elabora su libro dedicado a subrayar los puntos que se le muestran relevantes. Nosotros retomaremos la vinculación ente dos grandes entidades: $I$. La metáfora geológica y el estructuralismo; II. Mitos, metáforas, poesía.

I. La metáfora geológica y el estructuralismo. La realidad, entonces, es reconocida como algo que, mostrando su superficie, no es sino una invitación para iniciar su recorrido geológico, buscando lo que se ha sedimentado en sus diferentes capas constitutivas. "Un paisaje, considera Paz, como un rompecabezas: colinas, rocas, valles, árboles, barrancos: este desorden posee un sentido oculto; no es una yuxtaposición de formas diferentes sino la reunión en un lugar de distintos tiempos y espacios", justo 
como las capas geológicas. Como el lenguaje, este paisaje es diacrónico y sincrónico al mismo tiempo: es la historia condensada de las edades terrestres y es también un nudo de relaciones. ${ }^{3}$ Es la fuente y el manantial para comprender las propuestas de Lévi-Strauss y es el río que a Paz le place navegar junto con él. El de las realidades humanas como condensaciones de diferentes etapas terrestres. El fin último de la antropología estructural es contribuir al conocimiento del pensamiento objetivado. Todo elemento cultural, al encontrarse elaborado y sostenido por el pensamiento inconciente, permite al análisis interpretarlo como pensamiento en proceso continuo de objetivación, de materialización en la vida cotidiana. Así, al descubrimiento primario de la geología se unieron después el marxismo, como geología de la sociedad, y el psicoanálisis, como una geología síquica: Marx y Freud, como los geólogos, explican lo visible por lo oculto.

Por otro lado, la presencia de Mauss y Durkheim abonarán a la concepción del hecho social total. Lo cual implica que cada fenómeno, sin perder su especificidad, alude a otros fenómenos. Por lo cual, lo que cuenta no es la explicación global, sino la relación entre los fenómenos; la sociedad es una totalidad en cuanto es un sistema de relaciones, es "un circuito de relaciones entre todos los planos". ${ }^{4}$ En otras palabras, es un conjunto de signos, es decir, una estructura, la cual contiene un sistema total de relaciones que engloba tanto al aspecto material como jurídico, religioso y artístico.

La originalidad, que Paz reconoce en Lévi-Strauss, reside en ver la estructura no sólo como un fenómeno, resultado de la asociación de los hombres, sino como un sistema regido por una cohesión interna, donde cada sistema -ya sean las formas de parentesco o las mitologías, por ejemplo-es como un lenguaje que puede traducirse al lenguaje de otro sistema. Para el antropólogo francés, la estructura de un sistema está regido por un código, que si el antropólogo logra descifrar, le permitirá su traducción a otros sistemas. La búsqueda de este código es central. El código es inconciente y racional. En suma: lo inconsciente posee una racionalidad inmanente, cuestión que le permitió pensar que el sistema fonológico de la lingüística estructural le pareciera el modelo más acabado y universal de esa razón inconsciente, subyacente en los fenómenos sociales: ningún elemento del lenguaje puede ser valorado si no se le considera en relación con los otros elementos: de tal modo, la noción de relación se convierte en 
el fundamento de la teoría, el lenguaje en esto es transparente, es de manera contundente un sistema de relaciones. El lenguaje -y con él la sociedad entera, sus ritos, arte, economía, religión-es un sistema de signos, un signo de signos. Y con ello regresamos a la complicidad de ambos pensadores: todo lo que nombramos, dice Paz, ingresa al círculo de del lenguaje y, en consecuencia, a la significación.

II. Mitos. El mito ha pasado por diferentes momentos de aceptación. Si bien no podemos imaginar la antigüedad sin ellos, nos parece aceptable que en el mundo moderno puedan ser prescindibles, puesto que nos parecen incompatibles con las ideas claras y distintas que el cartesianismo perseguía. La pretendida oposición entre pensamiento lógico y pensamiento mítico no es sino el reflejo de nuestra ignorancia.

El estudio de los mitos-advierte Lévi-Strauss- plantea un problema metodológico en virtud del hecho de que no se puede conformarse al principio cartesiano de dividir la dificultad en tantas partes como haga falta para resolverla. No existe término verdadero del análisis mítico, ni unidad secreta para asir al final del trabajo de descomposición. Los temas se desdoblan hasta el infinito. Cuando se cree haberlos desenmarañado y tenerlos separados, simplemente se aprecia que vuelven a ligarse respondiendo a las solicitaciones de afinidades imprevistas. Por consiguiente, la unidad del mito no es sino de tendencia proyectiva, jamás refleja un estado o un momento del mito. Fenómeno imaginario implicado por esfuerzo de interpretación, su papel es conceder una forma sintética al mito e impedir que se disuelva en la confusión [...] La divergencia de las sucesiones $\mathrm{y}$ de los temas es un atributo fundamental del pensamiento mítico. Se manifiesta bajo el aspecto de una irradiación. ${ }^{5}$

Sabemos, considera Paz, leer un tratado de filosofía, pero no cómo deben leerse los mitos. Su significado se nos escapa porque el lenguaje ocupa en el mito un lugar parecido al del sistema fonológico dentro del mismo lenguaje: la pluralidad de los mitos en diferentes tiempos espacios es tan clara como la repetición en los relatos míticos de ciertos procedimientos. La elaboración mítica obedece a las mismas leyes de la lingüística: selección y combinación de signos verbales. El mito es habla, es lengua: una estructura que se actualiza cada vez que volvemos a contar al historia.

La sustancia del mito no se encuentra en el estilo, ni en el modo de la narración, ni en la sintaxis, sino en la "historia" relatada. El mito es

${ }^{5}$ Leví-Strauss, Mitológicas, vol. I. Lo crudo y lo cocido, 1972, México, FCE, p. 15. 
lenguaje, pero lenguaje que opera en un nivel muy elevado y cuyo sentido logra "despegarse", si cabe usar una imagen aeronáutica, del fundamento lingüístico sobre el cual había comenzado a deslizarse. ${ }^{6}$

"Las unidades constitutivas del mito son frases u oraciones mínimas que, por su posición en el contexto describen una relación entre diversos aspectos, incidentes y personajes del relato". Lévi Strauss propone que los denominemos mitemas. Los mitemas son nudos o haces de relaciones míticas y operan en un nivel superior al puramente lingüístico. El nivel más bajo corresponde a la estructura fonológica; el segundo a la sintáctica, común a todos los discursos; en el tercero, el discurso mítico propiamente dicho... Las combinaciones de mitemas deben producir mitos con la misma fatalidad y regularidad con que los fonemas producen sílabas, palabras, textos. ${ }^{7}$

Hay [...] que compenetrarse de la convicción de que detrás de todo sistema mítico se perfilan, como factores preponderantes que lo determinan, otros sistemas míticos: son ellos quienes hablan en él y se hacen eco los unos a los otros, si no hasta el infi-

${ }^{6}$ Leví-Strauss, Antropología estructural, 1968, México, FCE, p. 190.

${ }^{7}$ Octavio Paz, Claude Lévi-Strauss o el nuevo festín de Esopo, pp. 28-9. nito, cuando menos hasta el momento inasible en que, hace unos cientos de millares de años $-\mathrm{y}$ a lo mejor un día se dice que más-, la humanidad nueva profirió sus primeros mitos. Esto no significa que a cada etapa de este desarrollo complejo, el mito no inflexione pasando de una sociedad a otra en contigüidad con infraestructuras tecno-económicas diferentes, cuya atracción experimenta cada vez. ${ }^{8}$

El mito opera con el lenguaje como si éste fuera un sistema presignificativo. Es decir: lo que dice el mito no es lo que dicen las palabras del mito. Por ello los mitos nos enfrentan una y otra vez al problema del sentido de la significación. Lévi-Strauss piensa que el contenido del mito no es 10 importante, ni ofrece nuevas interpretaciones; lo que busca, lo que le interesa, es intentar descifrar su estructura: "el sistema de relaciones que lo determina y que probablemente es similar en los otros mitos". ${ }^{9}$ Éste es su punto de enfoque: el encontrar una ley general, formal y combinatoria. Esta idea y su búsqueda le llevan a estudiar cientos de mitos. Encuentra que la forma de operación del pensamiento mítico no es distinta a la de nuestra lógica, "difiere en el empleo de los símbolos porque en lugar de proposiciones, axiomas y signos abstractos

${ }^{8}$ Leví-Strauss, Mitológicas IV. El hombre desnudo, 1971, México, Sigo XXI, p. 568.

${ }^{9}$ Octavio Paz, op. cit., p. 30. 
se sirve de héroes, dioses, animales y otros elementos del mundo natural y cultural. Es una lógica concreta y no menos rigurosa que la de los matemáticos: la posición de los términos es privilegiada". ${ }^{10}$

Hay que tomar partido: los mitos no dicen nada que nos instruya acerca del orden del mundo o su destino. No puede esperarse de ellos ninguna complacencia metafísica; no acudirán al rescate de ideologías extenuadas. En desquite, los mitos, nos enseñan mucho más sobre las sociedades de las que proceden, ayudan a exponer los resortes íntimos de su funcionamiento, esclarecen la razón de ser de creencias, de costumbres y de instituciones cuyo plan parecía incomprensible de buenas a primeras; en fin, y sobre todo, permiten deslindar ciertos modos de operación del espíritu humano, tan constantes en el correr de los siglos y tan generalmente difundidos sobre inmensos espacios, que pueden ser tenidos por fundamentales y tratar de volver a encontrarlos en otras sociedades y dominios de la vida mental donde se sospechaba que interviniesen, y cuya naturaleza a su vez quedará alumbrada. ${ }^{11}$

Este punto, donde Lévi Strauss señala que la razón científica no es superior en términos lógicos al mito,

${ }^{10}$ Octavio Paz, op. cit., p. 36.

${ }^{11}$ Leví-Strauss. Mitológicas, vol. IV., op. cit., p. 577. es uno de los elementos que inquietan a Paz. Si por un lado festeja este hallazgo, por otro se muestra casi disgustado e irritado por la ambigüedad con el antropólogo francés y dice: "el método de Lévi-Strauss prohíbe un análisis del significado particular de los mitos: por una parte piensa que esos significados arbitrarios, contradictorios y en cierto modo, insignificantes. Por la otra afirma que el significado de los mitos se despliega en una región que está más allá del lenguaje". ${ }^{12}$ Este enfoque que parece no perseguir lo que los mitos significan, ni el por qué de su aparición histórica, parecen mostrar un interés meramente técnico, es decir, el modo en que se traducen de un sistema a otro, el código que les permite tener la necesaria cohesión interna que toda sociedad y toda tradición requiere para formar parte del mundo. Lo que reprocha Paz es esta carencia de preocupación histórica. Desde su punto de vista, el contexto histórico es una relación fundamental que permite la compresión del mito, y este ejercicio de comprensión le parece de gran relevancia y de ninguna manera algo prescindible.

El sistema de simbolizaciones se produce sin cesar. El mito engendra mitos que forman una espiral: la nueva versión lo modifica y, al mismo tiempo, lo repite. Por eso, considera Paz, la versión del Edipo de Freud es una

${ }^{12}$ Octavio Paz, op. cit., p. 38. 
versión más; incluso el estudio de Lévi-Strauss, siguiendo su propio planteamiento, sería también una versión más. "Cada mito, entonces, despliega su sentido en otro y así sucesivamente hasta que todas esas alusiones y significados tejen un texto, un grupo, una familia de mitos". Por otro lado, si el significado de un mito depende de su posición en el grupo para descifrarlo, es claramente necesario tener en cuenta el contexto en que aparece. El mito aparece entonces como una frase de un discurso circular y que cambia constantemente de significado: repetición y variación. Esta manera de considerar la vida de los mitos, dice, nos acerca a una conclusión vertiginosa: el grupo social que elabora el mito, ignora su significado. $^{13}$

Cada narrador $[\ldots]$ cuenta las historias a su manera. Hasta en detalles importantes la variación es enorme [...] Pero a los indígenas no parecía conmoverles esta situación [...] Un carajá que me acompañaba de pueblo en pueblo escuchó una porción de variantes de este tipo y las acogió todas casi con igual confianza. No es que no percibiera las contradicciones. Es que no le interesaban en lo más mínimo. ${ }^{14}$

${ }^{13}$ Ibid., pp. 38-9.

${ }^{14}$ Lévi-Strauss, Mitológicas vol. I, op. cit., p. 22.
Nadie sabe que el relato en cuestión es parte de un inmenso poema, en el que los mitos se comunican entre ellos por medio de los hombres $\mathrm{y}$, además, sin que lo sepan. ${ }^{15}$ Parecería coincidir esta idea con la de románticos, cuando señalaban que el lenguaje hablaba por medio del poeta y no el poeta a través del lenguaje. Sin embargo, si bien el poeta podía sentirse y aceptar su condición de mediador, el hombre que vive y narra el mito no sabe que es parte o medio de una mitología. La conciencia en este sentido no es más que una ilusión, por ello carece de importancia y de fuerza teórica el que el narrador del mito tenga idea de qué está haciendo. Aquí Paz parece lamentar las conclusiones que las premisas de Lévi-Strauss le hacen inferir. Le parece que en este punto sus observaciones se vuelven oscuras y paradójicas.

La razón de esta paradoja reside en la naturaleza dual del mito. El mito es una historia contada con palabras, es una estructura presignificativa sobre la cual se edifica el verdadero discurso mítico. La cuestión es que este segundo discurso trasciende, según Lévi-Strauss, el lenguaje articulado, que traduce en sistema de relaciones, fórmulas y ecuaciones. El desacuerdo es abierto y Paz rebate planteando que en el mito la estructura presignificativa es ya significativa. Y aquí

\footnotetext{
${ }^{15}$ Octavio Paz, op. cit., p. 39.
} 
aparecería la segundad dificultad: el verdadero discurso mítico sería intraducible ya que trascendería el lenguaje articulado. En suma: qué dice realmente el mito, sería algo que escaparía a la intención y posibilidad de descifrarlo.

Podría decirse, siguiendo estos postulados, que las civilizaciones se han comunicado entre ellas sin que quienes han elaborado estas comunicaciones se hayan dado cuenta. Según Lévi-Strauss, los sistemas mitológicos indoeuropeos y americanos muestran su relación, así como el mundo mongol y el indoeuropeo. El sistema americano podría ser el punto de unión, de mediación entre estos sistemas míticos. La universalidad de la razón podría quedar entonces demostrada por la acción de un pensamiento que hasta hace poco llamábamos irracional o pre-lógico, lo cual podría derivar en una hipótesis: que las posibles coincidencias serían resultado del espíritu humano.

En síntesis, dirá Paz, la comunicación social mediante el mito que plantea Lévi-Strauss, intenta resolver la heterogeneidad de las historias particulares en una estructura atemporal. Esta interpretación tendría un lado vivificante: no habría pueblos marginales y la pluralidad de las culturas sería ilusoria, pues se resolvería en una pluralidad de metáforas coincidentes. "Hay un punto entonces en donde se cruzan los caminos y éste es el espíritu humano, que obedece en todas partes y en todos los tiempos a las mismas leyes". ${ }^{16}$ La búsqueda del maestro antropólogo hacia lo universal está por encima del recuento de la historia y de la mirada del científico ceñido al dato.

A fin de cuentas, el tema de todos los mitos es la lucha entre la cultura y la naturaleza. La cultura como la edificación protectora, significada, metafórica y la naturaleza. Tal como se expresa en la creación humana por excelencia: la cocción de los alimentos por el fuego domesticado. La diferencia entre lo crudo y lo cocido. Tema prometeico de enormes resonancias; recordemos, entre otras, la escisión entre los dioses y el hombre, la vida perenne del cosmos y la finitud humana. Sin duda, es el tema central de las meditaciones de Lévi-Strauss: el lugar del hombre en la naturaleza. La posibilidad de lo crudo y lo cocido, junto con la prohibición del incesto, separan y unen al mundo natural y al humano. Ambos están prefiguradas en el lenguaje que es lo que nos separa de la naturaleza y, a la vez, lo que nos une a ella y a nuestros semejantes. El lenguaje significa la distancia, advierte Paz, entre el hombre y las cosas, tanto como el deseo de anularla, el deso de que desaparezca esta distancia. Paradoja insalvable. Somos

${ }^{16}$ Ibid., p. 44. 
en distancia con la naturaleza. "La cocina y el tabú del incesto, son homólogos del lenguaje". Ambas son mediaciones: la primera entre lo crudo y lo cocido, la segunda entre la endogamia y la exogamia. El modelo de ambas mediaciones es la palabra. Puente entre el grito y el silencio. Mediaciones, palabras, signos que cambian el torrente amorfo de la vida por la aparición de familias de símbolos. Cocina, tabú del incesto y lenguaje son operaciones del espíritu, pero, señala Paz, el espíritu es una operación de la muerte. Y aquí echa en falta alguna referencia a ella en la vasta obra del antropólogo francés; desde su perspectiva, es imposible no incorporarla en el ejercicio reflexivo, pues ella es la diferencia, la raya divisoria, el sentido último de nuestras metáforas. La muerte, sentencia, nos condena a la cultura. ${ }^{17}$

\section{III}

Metáforas. El ser carencial que es el hombre y cuya fragilidad es el punto medular para una pregunta antropológica central, a saber, "cómo ése ser es capaz de existir"; en términos generales, puede responderse: gracias a que es capaz de establecer relaciones de mediación con la realidad, es decir, gracias a que la relación del

\footnotetext{
${ }^{17}$ Ibid., pp. 48-9.
}

hombre con la realidad es indirecta, mediada, metafórica, simbólica, significada. Aquí es necesario detenerse, reflexionar en esta propuesta que considera al pensamiento como una posible tarea de desciframiento, de clarificación de las claves de lo que nos rodea, de adentrarnos en la brumosa realidad ayudados por la posibilidad de encontrar la cadena de significados que los fenómenos establecen. Baltasar Gracián lo expresa claramente: "descifrar el mundo significa $[. .$.$] tener una actitud serena ante$ la verdad $[. .$.$] No se trata de revela-$ ciones o misterios trascendentes, sino sólo de ir leyendo junto con el texto que se tiene a la vista su fondo de sentido. Ante todo el libro del mundo no es el libro de la naturaleza, ni siquiera de la naturaleza humana". ${ }^{18}$

Que el mundo sea algo a descifrar nos remite a la cuestión de por qué esta cifrado. Detrás de ello, está la necesidad humana de cubrir la desnudez de las cosas. Las metáforas no pueden sino expresar los diferentes componentes tanto de las elaboraciones míticas como de las elaboraciones científicas para mostrar la necesidad de significación. La realidad se ha ido humanizado a través de metáforas. La actividad simbólica del hombre nace para ayudar a lidiar con las potencias

${ }^{18}$ Baltasar Gracián, citado en Hans Blumenberg, La legibilidad del mundo, 2005, Barcelona, Paidós, p. 117. 
de la realidad física, con las potencias de la naturaleza.

La reconsideración de las elaboraciones metafóricas toma importancia al considerar que lo que podemos saber acerca de nosotros mismos encuentra su mejor expresión en la elaboración metafórica. Así, para descifrar nuestro mundo y poder acercarnos a sus secretos subterráneos requerimos mantener una continua mediación: "la referencia humana a la realidad es indirecta, ardua, retardada, selectiva y, por encima de todo, metafórica". ${ }^{19}$

El sentido de la significación y la creación metafórica son elementos hermanados, son hijos del espíritu humano que se expresa en la misma clave en todas las sociedades.

Música y Poesía. Lévi-Strauss sostiene en el libro Lo crudo y lo cocido que entre la música y el mito existe una analogía. Lo que, desde la perspectiva de Paz, sería más natural que se diera ente el mito y el poema. "Música y mito, señala Lévi-Strauss, son lenguajes que trascienden, cada uno a su manera el lenguaje articulado." Para Paz, la música no puede trascender el lenguaje articulado puesto que su clave no es lingüística. Considera que la música es como las otras artes no verbales: un sistema de comunicación análogo, pero de ninguna manera idéntico al lenguaje verbal. Por otro

${ }^{19}$ Blumenberg, citado en F. J. Wetz, Hans Blumenberg. La modernidad y sus metáforas, p. 16. lado, "como el mito, aunque en dirección contraria, la poesía si trasciende le lenguaje." La movilidad de los signos lingüísticos permite que "las palabras expliquen a las palabras"; toda frase dice algo que puede ser dicho por otra frase, todo significado puede ser dicho de otra manera. La frase poética, la unidad mínima del poema, es un decir irrevocable y final en el que sonido y sentido se funden, sostiene Paz. La poesía trasciende el lenguaje, ya que modifica continuamente ese conjunto de signos dinámicos e intercambiables que es el lenguaje; por ello, puede ser un decir último. Podemos comprender que es una posición drástica, definitiva: para el poeta mexicano, el sistema de comunicación más perfecto es, sin duda, el lingüístico. ${ }^{20}$

Encontrar la conexión entre mito y poema se fundamenta en la noción de función poética. Dentro de ésta, el poema lírico ocupa un extremo y el mito otro. "Entre el poema lírico y el mito hay un término intermedio: la poesía épica". El mito, entonces, se sitúa en una de las fronteras de la función poética: éste no puede ser poema, ni ciencia, ni filosofía, aunque coincida con el poema por su función poética, con la ciencia por su lógica y con la filosofía por su deseo de ofrecernos una idea del universo. LéviStrauss, piensa Paz, se ha quitado la

${ }^{20}$ Octavio Paz, op. cit., p. 54. 
soberbia del filósofo gracias a la humildad del hombre de ciencia, pero no ha logrado liberarse del malhumor que le produce la poesía. ${ }^{21}$

En conclusión, la admiración que sintió Octavio Paz por la obra de Lévi-Strauss nos ha dejado este texto reflexivo, en el cual el poeta, pero sobre todo el humanista crítico, muestra los reflejos que encontró a sus inquietudes. A veces como ecos discordantes y, por lo mismo, mostrando abiertamente su oposición; a veces, con el entusiasmo de una nueva comprensión. Los hallazgos de Lévi-Strauss, su descubrimiento de que hay una misma clave lógica en el pensamiento del primitivo, del salvaje, del silvestre, similar a la de las sociedades donde el entendimiento se presume diferen- te en tanto científico y racional; la importancia del pensamiento mítico y su elaboración universal donde se muestra que el espíritu humano pertenece a toda la humanidad en la misma medida; el reconocimiento de que el lenguaje es una vía de expresión por excelencia, donde no sólo se da la comunicación y transmisión de saberes, sino que además se estructura los sistemas fundamentales de la vida social ya que el hombre es, fundamentalmente, un emisor de signos, a la vez que se conforma como un signo entre los demás signos, son los elementos que entretejen este dialogo. Parafraseando a Borges: "quizá la historia universal es la historia de la diversa entonación de algunas metáforas", y agregamos, de algunos mitos. 